\title{
Multiple hedonic memory: Memory for more than one hedonic event in rats
}

\author{
E. J. CAPALDI, DONNA R. VERRY, and TIMOTHY M. NAWROCKI \\ Purdue University, West Lafayette, Indiana
}

\begin{abstract}
In each of two investigations, rats ran in a runway to obtain varying quantities of food pellets presented in a fixed order, such as 20-0-20. The major finding was that rats ran faster on a 0 pellet trial if that trial was followed shortly by a 20-pellet trial (e.g., 20-0-20 series) than if it was not (e.g., 20-0 series). This finding was obtained both within groups (Experiment 1) and between groups (Experiment 2), and suggested that the memory of 20 pellets arising from the first trial of the 20-0-20 series was retrieved not only on the second trial of the series, thereby signaling 0 pellets, but on the third trial as well, thereby also signaling 20 pellets. Retrieving the memory of 20 pellets on Trial 3 of the 20-0-20 series apparently resulted in that memory's elevating speed on Trial 2 of that series.
\end{abstract}

Rats remember hedonic events such as reinforcement and nonreinforcement, and these memories can exercise considerable control over responding in a wide variety of instrumental learning tasks (e.g., Capaldi, 1966; Capaldi, Verry, \& Davidson, 1980; Grosslight \& Radlow, 1956; Haggbloom, 1980; Haggbloom \& Tillman, 1980; Seybert, Mellgren, Jobe, \& Eckert, 1974). Understanding this behavioral control, however, depends upon how many hedonic events are remembered in particular situations: the animal may remember only the immediately prior hedonic event (single-event hedonic memory) or two or more prior hedonic events (multiple-event hedonic memory). The single-event hypothesis has proved capable of explaining a wide variety of instrumental learning effects (see, e.g., Capaldi, Nawrocki, \& Verry, 1982; Capaldi et al., 1980). Despite this, single-event hedonic memory may not adequately describe what occurs in the typical instrumental learning situation, because, as has recently become abundantly clear, rats are capable of remembering many hedonic events, a minimum of at least eight (Capaldi \& Verry, 1981). The question is: Do rats normally exercise their highly developed capacity to remember hedonic events? If they do, then multipleevent hedonic memory could be a major factor regulating responding in all instrumental learning situations (see Capaldi \& Verry, 1981).

But rats may employ their considerable capacity to remember two or more hedonic events only when this provides some benefit, as, for example, in allowing the animal to better predict the occurrence of reinforcement. This was the case in the tasks employed by Capaldi and Verry (1981), since, in certain in-

This research was supported by NSF Grant BSN 80-01171 to E. J. Capaldi. The author's mailing address is: Department of Psychology, Purdue University, West Lafayette, Indiana 47907. stances, the presence or absence of food reinforcement could be predicted only by remembering two or more hedonic events. But in the instrumental learning tasks in common use, multiple-event hedonic memory is seldom the sole or even the best means available for predicting reinforcement. Furthermore, as Capaldi and Verry have indicated, when other cues reliably signal reinforcement, employing multiple-event hedonic memory may reduce rather than augment anticipatory responding. What Capaldi and Verry may have shown, then, is that rats are capable of employing multiple-event hedonic memory and that they do so in the rare cases in which it is the only means available for predicting reinforcement. Alternatively, rats may employ multiple-event hedonic memory when it is redundant, i.e., when other cues signal reinforcement as well.

Each of the two investigations reported here had the following characteristics: A learning task was provided that could be mastered employing either single-event or multiple-event hedonic memory. Which was employed would be revealed by running speed on nonreinforced trials. If multiple-event hedonic memory was employed, speed on nonreinforced trials would be elevated. The reasoning behind the present investigations was as follows. If multipleevent hedonic memory was employed by rats when some other method of solution was available, and employing multiple-event hedonic memory elevated speed of responding on nonrewarded trials as well, it would appear that rats normally attempt to remember more than one hedonic event.

\section{EXPERIMENT 1}

One of the more direct ways of examining hedonic memory was employed here: hedonic serial learning. Rats were trained in a runway and provided with 
varying numbers of $.045-8$ pellets arranged in a regular repeating, and therefore predictable, order. For example, the rat might receive the three hedonic events, each separated by a 30-sec interval, in the following manner: 20 pellets followed by 0 -pellet nonreinforcement followed by 20 pellets. This is written 20-0-20. The rat would be said to have learned this series if it ran fast on each of the 20-pellet trials and slowly on the 0-pellet trial. Such anticipatory responding is regarded (see, e.g., Capaldi \& Molina, 1979) as a form of discrimination learning in which the memories of hedonic events serve as the cues signaling reinforcement $(\mathrm{S}+$ cue) and nonreinforcement (S- cue).

Either single-event or multiple-event hedonic memory can be employed to learn the series of three events 20-0-20. Under either method of learning, the $\mathrm{S}-$ cue, the memory that signals 0-pellets, would be $\mathrm{S}^{20}$, the memory of the first event of the series, 20 pellets. It is the case, of course, that when two or more hedonic events can be remembered, differences between single-event and multiple-event hedonic memory can arise. Thus, the memory signaling the third event of the series, 20 pellets, would differ depending upon the method employed to learn the series. If single-event hedonic memory were employed, the $\mathrm{S}+$ cue signaling 20 pellets would be $\mathrm{S}^{\mathbf{0}}$, the memory of the second, or 0-pellet, event of the series. And if multiple-event hedonic memory were employed, the $\mathbf{S}+$ cue would be the memory of the first two hedonic events of the series, written as $\mathbf{S}^{20}$ $+\mathrm{S}^{0}$.

The implication is that the discrimination learning problem would be much easier if single-event rather than multiple-event hedonic memory were employed. This is because the $\mathbf{S}-$ and $\mathbf{S}+$ cues are more dissimilar when single-event hedonic memory $\left(\mathbf{S}^{20} \mathrm{vs} . \mathrm{S}^{0}\right.$, respectively) is used than when multiple-event hedonic memory ( $S^{20}$ vs. $S^{20}+S^{0}$, respectively) is used. Clearly, it should prove difficult to inhibit responding in the presence of the $S-c u e, S^{20}$, when that cue is part of the $\mathbf{S}+$ stimulus complex, $\mathbf{S}^{20}+\mathbf{S}^{0}$. It is clear, then, that, in connection with the 20-0-20 series, the use of multiple-event hedonic memory would elevate responding to nonreward.

Experiment 1 may best be understood as an attempt to detect whether rats tried to learn a series such as the $20-0-20$ series by using single-event or multiple-event hedonic memory. Experiment $1 \mathrm{em}$ ployed two groups, both of which received two series, one of three events and one of two events. The two series occurred equally often and irregularly, such that the rat could not determine which of the two series it was to receive. Group 20-0-20 received the two series $20-0-20$ and $2-0$. Oroup 2-0-20 received the two series $2-0-20$ and 20-0. Each group could learn both its series by employing single-event hedonic memory. If they did so, then anticipating 0 pel- lets would be no 'more difficult in the three-event than in the two-event series. However, if multipleevent hedonic memory were employed, running would be faster to 0 pellets in the three-event than in the two-event series.

\section{Method}

Subjects. The subjects were 16 naive male albino rats, about 80 days old on arriving at the laboratory, that had been purchased from the Holtzman Company, Madison, Wisconsin.

Appanatus. The apparatus was a straight-alley runway painted flat gray throughout and measuring $195.58 \mathrm{~cm}$ in length, $9.84 \mathrm{~cm}$ in width, and $13.33 \mathrm{~cm}$ in height. The alley had a hinged $1.3-\mathrm{cm}$ hardware cloth top. The first $23.18 \mathrm{~cm}$ of the runway was closed off by an aluminum door to form the startbox. The closing of the startbox door was $3 \mathrm{sec}$ after the rat had been placed in the apparatus started the first of three completely silent electronic $.01-\mathrm{sec}$ clocks. Interruption of a photobeam $15.24 \mathrm{~cm}$ from the startbox door stopped the first clock (start time) and started the second clock. Interruption of a second photobeam $104.14 \mathrm{~cm}$ from the first photobeam stopped the second clock (run time) and started the third clock. Interruption of a third photobeam $38.73 \mathrm{~cm}$ from the second and $6.03 \mathrm{~cm}$ in front of the wooden goalcup stopped the third clock (goal time). When the rat had broken the third photobeam, an aluminum door was lowered to confine the rat to the $36.19-\mathrm{cm}$ goalbox. The sum of the elapsed time on the three clocks was called the total time.

Procedure. On arrival at the laboratory, the rats were caged individually and given unlimited access to food and water for 10 days. On Day 1 of pretraining, all food was removed from the home cages, and the rats were maintained on $14 \mathrm{~g} /$ day of Wayne Lab Blox for the remainder of the experiment. Water was always available in the home cages. On Days 1-8, the rats were handled for $1 \mathrm{~min}$. On Days 9 and 10, the rats were given $1 \mathrm{~min}$ of unbaited alley exposure. On Days 8-10, the rats were each given $20.045-\mathrm{g}$ Noyes food pellets in the home cages. This food was subtracted from the daily ration of Lab Blox to maintain the total amount of food eaten at $14 \mathrm{~g}$ day. On Day 10 of pretraining, the rats were randomly divided into two groups of eight each, Group 20-0-20 and Group 2-0-20.

Experimental training began on Day 11 . In experimental training, which lasted 26 days, each rat received two series, one of three events and one of two events, each series occurring twice each day. Group 20-0-20 received the two series 20-0-20 and 2-0. Group 2-020 received the series $2-0-20$ and $20-0$. The interval elapsing between the trials of a series was about $20 \mathrm{sec}$, and the interval elapsing between series presentations was about $20-30 \mathrm{~min}$. The rat was placed in the startbox, and, if the $20-0-20$ series was scheduled, it was given 20 pellets after reaching the goalbox. After eating the 20 pellets, the rat was placed in a holding cage and about $20 \mathrm{sec}$ later was given the 0-pellet, or nonreinforced, event. Then it was given the 20-pellet event and placed in the holding cage to await the next series of the day, given about 20-30 min later. In the 20-30-min interval, other rats in the squad were run. The rats of a squad were returned to the home cage only after all rats in the squad had been run.

There were two experimenters, each of whom ran four rats from each group. Bach experimenter brought the eight rats into the experimental room from the colony room and placed them in holding cages, which contained water for drinking. The running order of the eight rats was randomized daily. Series presentation was as follows. On odd numbered days it was $20-0-20,2-0,2-0$, and 20-0-20 for Group 20-0-20 and 20-0, 2-0-20, 2-0-20, and 20-0 for Group 2-0-20. On even numbered days it was $2-0,20-0-20$, $20-0-20$, and $2-0$ for Groups $20-0-20$ and $2-0-20,20-0$, and $2-0-20$ for Group 2-0-20.

Three seconds after a rat had been placed in the startbox, the startbox door was lowered. The rat was given $60 \mathrm{sec}$ to traverse each alley section, for a total maximum time of $180 \mathrm{sec}$. If the rat 
had not traversed a particular alley section within $60 \mathrm{sec}$, a time of $60 \mathrm{sec}$ was assigned to that section and the remaining time was assigned to the next alley section. If the rat had not entered the goalbox within $180 \mathrm{sec}$, it was gently placed in the goalbox. The rat was removed from the goalbox after having eaten the pellets, or after $30 \mathrm{sec}$ on 0 -pellet events. Following training, the rats were returned to the home cages and, about $15 \mathrm{~min}$ later, received the daily ration of food, minus the amount eaten in the apparatus.

\section{Results}

The following comments apply to Experiments 1 and 2. All times were converted to speeds (in $\mathrm{cm} / \mathrm{sec})$. Only total speed is reported, since results did not vary as a function of alley section. Statistical tests adopted the .05 level of significance, and only the $F$ values for significant differences are reported.

The major findings obtained in Experiment 1 can be summarized quite simply. Running was fast and nondifferential to reinforced events and slow to 0 pellet events, with each group faster to the 0-pellet event of its three-event series than to the 0-pellet event of its two-event series. Running speeds on reinforced trials were fast and nondifferential, both on a within-group and a between-group basis.

The major findings in Experiment 1 are shown in Figure 1. Figure 1 shows speed of running for each group to the 0-pellet events of its three-event and two-event series. Three trends may be noted in Figure 1. First, over the early training blocks, speeds were nondifferential and tended to increase. However, as training continued, both groups learned to run slowly to the 0 -pellet events. Finally, these speed reductions were greater in both groups to the 0-pellet event of the two-event series than to the 0-pellet event of the three-event series. An analysis of variance on the speeds shown in Figure 1 included as factors groups (20-0-20 vs. $2-0-20)$, series length (three- vs. two-event series), experimenters, and blocks. Only series length was significant $[F(1,12)=37.10, p<$ $.001]$.

The following analyses of variance were also performed. To determine if speed differences were associated with reinforced events, the first and third events were analyzed separately. To determine if 0 -



Figure 1. Speed of running along the total length of the runway for each group on the 0-pellet event of ench of its two series In blocks of 2 days. pellet events were anticipated, each series received by each group was analyzed separately. These analyses produced only one significant difference: In each series, each group ran more slowly to its 0-pellet event than to its reinforced events. Thus, in Group 20-0-20, we have $F(2,12)=51.00, p<.001$, for its three-event series and $F(1,6)=176.51, p<.001$, for its two-event series. The corresponding $F$ values for Group 2-0-20 are 21.59 and 76.07 , respectively. Subsequent Newman-Keuls tests applied to each three-event series indicated that 0 -pellet events differed from reinforced events ( $\mathrm{ps}<.01$ ) and that speeds to reinforced events did not differ. That running was slower on nonreinforced than on reinforced trials, with differences failing to occur on reinforced trials, may be illustrated by presenting speeds for reinforced trials on Block 13, the last block of training trials. In Group 20 $0-20$, these speeds were 99.22 and $102.46 \mathrm{~cm} / \mathrm{sec}$ on the first and third trials of its 20-0-20 series and $99.98 \mathrm{~cm} / \mathrm{sec}$ on the first trial of its $20-0$ series. The comparable speeds for Group 2-0-20 were, respectively, 100.36, 101.06, and $102.00 \mathrm{~cm} / \mathrm{sec}$. Finally, it is of interest to note that the interaction of blocks $X$ series length $\times$ groups was significant $[F(12,144)=$ $7.82, p<.001$ ]. Subsequent Newman-Keuls tests indicated that Group 2-0-20 ran significantly faster than Group 20-0-20 on 0-pellet trials of the threeevent series on Blocks 9 and 10 and that no other difference between the groups was significant.

\section{Discussion}

Each group anticipated the second, or 0-pellet, event of each of the two series it received by running slowly. The critical finding obtained in Experiment 1 was that, in both groups, running was faster on 0pellet trials in the three-event series than in the twoevent series. This finding indicates that, despite the availability of single-event hedonic memory, both groups employed multiple-event hedonic memory to learn the series. We turn now to consider the memories used by each group to anticipate the second event of each series and the memories used to anticipate the third event of each three-event series.

The $S$ - cues employed by each group would not be affected by the method used to learn the series, and for both groups the $S-$ cues were the same, $S^{20}$ and $S^{2}$. For Group 20-0-20, $S^{20}$ became an $S$ - cue under the 20-0-20 series and $S^{2}$ became an $S-$ under the 2-0 series. For Group 2-0-20, $S^{2}$ became an $S-$ cue under the 2-0-20 series and $S^{20}$ became an $S-$ under the 20-0 series. Consider now the $S+$ cue.

If single-event hedonic memory had been employed, then the $S+$ cue would have been $S^{0}$ in both groups. If this had been the case, the two groups would have been identical, having the same $S$ - cue, $S^{20}$ and $S^{2}$, and the same $S+$ cue, $S^{0}$, and there would be no basis for running faster on 0-pellet trials in the three-event than in the two-event series. Thus, the major finding obtained in Experiment 1 cannot be 
explained on the basis of single-event hedonic memory. However, the finding that running speed on 0 pellet trials was greater in the three-event than in the two-event series in each group can be explained on the basis of multiple-event hedonic memory.

If multiple-event hedonic memory had been employed, then the $S+$ cue would have been $S^{20}+S^{0}$ in Group 20-0-20 and $S^{2}+S^{0}$ in Group 2-0-20. The $S+$ cue of each group, then, would have been more similar to the $\mathbf{S}$ - cue of its three-event series than to the $\mathbf{S}$ - cue of its two-event series, thus producing in each group poorer anticipation of 0 pellets in the three-event than in the two-event series. That is, $S^{20}+S^{0}$ is more similar to $S^{20}$ than to $S^{2}$ (Group 20$0-20$ ), and $S^{2}+S^{0}$ is more similar to $S^{2}$ than to $S^{20}$ (Group 2-0-20).

In addition to the single-event hedonic memory hypothesis, other hypotheses are unable to explain the present results. A popular view in human serial learning is that serial ordering can be learned by associating each event with some representation of its position in the series (see, e.g., Crowder, 1976). But the 0-pellet event occupied the second or same position in both series. Thus, the serial position hypothesis, in common with a variety of other hypotheses such as counting events, counting responses, employing time cues, and so on, provides no basis for explaining poorer anticipation of 0 pellets in threeevent than in two-event series (see Capaldi \& Verry, 1981). According to another recent view (e.g., Hulse, 1978), rats anticipate events by encoding the rule structure of the series. But encoding a single rule would not allow the rat to run faster to 0 pellets in its three-event than in its two-event series. What is lacking in all these hypotheses, of course, is the recognition that the rat remembers the hedonic events of the series. Without that assumption, it may well be impossible for any hypothesis to explain the present results (see Capaldi \& Verry, 1981).

\section{EXPERIMENT 2}

Experiment 1 was the first investigation to concern itself with whether rats would employ multiple hedonic memory when a simpler method of learning was available, in this case single-event hedonic memory. It was important, therefore, to determine if the findings obtained in Experiment 1 were general. Experiment 2 was concerned with such generality, attempting to determine if findings similar to those obtained in Experiment 1 could be obtained under somewhat different experimental conditions.

Of the three groups employed in Experiment 2, Group Serial received the serial task 20-0-20. Group PA received two "paired-associate" events, 20-0 followed 30 min later by the events 0-20. Group MPA received the modified paired-associate task, 20-0 followed 30 min later by a single 20-pellet event.
Of major concern in Experiment 2 was anticipatory responding in each group on the second event of each day, the 0-pellet event common to all groups. For each group, the $S$ - cue signaling the second event of each day was $S^{20}$, the memory of the initial 20-pellet event received by each group. As for the S+ cues, if Group Serial employed single-event hedonic memory, the $\mathbf{S}+$ cue would be $\mathbf{S}^{0}$, and if Group Serial employed multiple-event hedonic memory, its $\mathrm{S}+$ cue would be $\mathbf{S}^{20}+\mathrm{S}^{0}$.

In Group PA, the $\mathbf{S}+$ cue was $\mathbf{S}^{0}$. The memory $\mathbf{S}^{0}$ became an $\mathrm{S}+$ cue in Group PA when it received the events $0-20$. There was no hedonic $S+$ cue for Group MPA; the S+ cue in Group MPA on the 20-pellet event, which occurred in isolation following the 30min interval, was other than a hedonic event. That the $\mathrm{S}+$ cues were, in fact, the $\mathrm{S}+$ cues for Groups PA and MPA is indicated by the findings of Capaldi and Verry (1981). They found that rats group, or "chunk," hedonic events occurring at a short interval and treat them as being separate from hedonic events that may occur subsequently after a long interval.

\section{Method}

Subjects. The subjects were 18 rats of the same description as in Experiment 1.

Apparatus. The runway employed in Experiment 2 was very similar to that employed in Experiment 1, differing only as follows: it was $45.2 \mathrm{~cm}$ longer, $9.6 \mathrm{~cm}$ higher, and $1.8 \mathrm{~cm}$ wider. The startbox and goalbox were shorter by 10.18 and $5.08 \mathrm{~cm}$, respectively. The distance from the startbox door to the first photocell was $11.18 \mathrm{~cm}$ shorter (start time), from the first photocell to the second, $25.25 \mathrm{~cm}$ longer (run time), and from the second to the third, $.32 \mathrm{~cm}$ longer (goal time). The third photocell was $1.59 \mathrm{~cm}$ farther back from the goalcup.

Procedure. Preliminary training in Experiment 2 was the same as in Experiment 1.

All aspects of experimental training in Experiment 2 were the same as in Experiment 1 except for the following. There were one experimenter and three groups in Experiment 2. All 18 rats were taken into the experimental room in their home cages. Group Serial received the events 20-0-20 each day. Group PA received the events $20-0$ followed about 30 min later by the events $0-20$. Group MPA received the events $20-0$ followed about 30 min later by a single 20-pellet event.

\section{Results}

As in Experiment 1, running was fast and nondifferential to reinforced events and slow to nonreinforcement. The major findings obtained in Experiment 2 are shown in Figure 2, which shows running speed for each group in blocks of two days to the common 0-pellet event, the second event of each day. As is clear in Figure 2, the groups differed little early in training. However, slow running to the 0 -pellet event developed first in Group MPA, then in Group PA, and finally in Group Serial. An analysis was performed on the speeds shown in Figure 2, using groups, blocks, and days as factors. This analysis indicated that the groups differed significantly $[F(2,15)=5.77, p<.01]$ and that the groups $\times$ blocks 




Figure 2. Speed of running along the total length of the alley for each group on the common 0 -pellet event, the second event of each day, in blocks of 2 days.

interaction was significant $[F(24,180)=3.52$, $p<.001]$. Because differences between Group Serial and Group MPA developed earlier in training than differences between Group Serial and Group PA, it was decided to break down the significant Group $X$ Blocks interaction with Newman-Keuls posttests on each block. Group Serial differed significantly from Group MPA on all blocks except Blocks 1, 2, 12, and 13. Group PA differed significantly from Group MPA on Blocks 3 and 4. Finally, Group Serial differed from Group PA on each of Blocks 7-11.

The following analyses of variance were also performed. To determine if speed differences were associated with reinforced events, the first and last reinforced events of each day were analyzed separately. To determine if 0 -pellet events were anticipated, all the events received by each group were subjected to separate analysis. Only one difference was significant: each group ran more slowly to 0-pellet events than to reinforced events. Thus, in Group Serial we have $F(2,10)=7.32, p<.02$. The corresponding $F$ value for Group MPA is $F(2,10)=283.68$, and for Group PA it is $F(3,15)=53.16$. Subsequent Newman-Keuls tests indicated that, in each group, running was slower to the 0 -pellet events than to the reinforced events (ps $<.01$ ), no other difference being significant. That running was slower on nonreinforced than on reinforced trials, with differences failing to occur on reinforced trials, is illustrated by the speeds on reinforced trials for Block 13, the last block of training trials. In Group 20-0-20, these speeds were 101.22 and $100.15 \mathrm{~cm} / \mathrm{sec}$ for the first and third trials of its series. The comparable speeds for Group MPA were, respectively, 102.21 and $104.45 \mathrm{~cm} / \mathrm{sec}$, and for Group PA they were 104.15 and $101.55 \mathrm{~cm} / \mathrm{sec}$.

\section{Discussion}

In Experiment 2, it was found that running speed on the second trial of the day, the 0-pellet event common to all groups, was greatest in Group Serial, intermediate in Group PA, and least in Group MPA. Better anticipation of this 0-pellet event by Group PA relative to Group Serial suggests that in Experiment 2, as in Experiment 1, multiple-event hedonic memory was employed despite the availability of single-event hedonic memory.

Groups PA and Serial had the same S- cue, $\mathbf{S}^{20}$. If Group Serial had employed single-event hedonic memory, it would also have had the same $S+$ cue as Group PA, $\mathrm{S}^{\circ}$, and there would be no basis for explaining superior anticipatory responding in Group PA. However, poorer anticipatory responding in Group Serial relative to Group PA can be understood as follows. Group Serial employed multiple hedonic memory, and, thus, its $S+$ cue was $\mathbf{S}^{20}+\mathbf{S}^{0}$. Since the cues $S^{20}$ vs. $S^{20}+S^{0}$ (Group Serial) are more similar than the cues $\mathrm{S}^{20}$ vs. $\mathrm{S}^{0}$ (Group PA), Group Serial had the harder discrimination-learning problem and, consequently, showed poorer anticipatory responding than did Group PA. Better anticipation by Group PA than by Group Serial appears to disconfirm an idea central to the singleevent hedonic memory hypothesis. According to that view, any serial task should be reducible to an appropriate number of paired-associate tasks. For example, the three event series 20-0-20 should be reducible to the two paired-associate tasks $20-0$ followed by $0-20$ because, under either method of training, the animal would learn that $S^{20}$ signals 0 and $S^{0}$ signals 20 . Better anticipation by Group PA than by Group Serial clearly suggests that a serial task is not reducible to a number of paired-associate tasks. This lack of reducibility is, however, in complete conformity with the multiple hedonic memory view. According to that view, there will always be a lack of equivalence between what is learned in a serial task and what is learned in a number of corresponding paired-associate tasks, because in serial tasks several prior events in the series are remembered.

The S- cue in Group MPA, as in Groups Serial and $\mathbf{P A}$, was $\mathrm{S}^{20}$. Considerations employed to explain the difference between Groups Serial and PA need only be extended a step to explain the rapid development of anticipatory responding in Group MPA. In Group MPA, as indicated, the S+ cue signaling 20 pellets was other than a hedonic memory. Thus, the discrimination learning problem for Group MPA was very easy ( $\mathrm{S}^{20}$ vs. nonhedonic $\mathrm{S}+$ cue), easier than in Group PA ( $\mathbf{S}^{20}$ vs. $\mathbf{S}^{0}$ ) and much easier than in Group Serial, which had the most difficult discrimination problem $\left(S^{20}\right.$ vs. $\left.S^{20}+S^{0}\right)$.

Now consider other hypotheses. A serial-position hypothesis appears to suggest, erroneously, better anticipation of the second event by Group Serial than by Group PA. This is because the second position was never reinforced in Group Serial, but was reinforced on $50 \%$ of the occasions in Group PA (0-20 
events). Similar erroneous predictions would seem to follow from other hypotheses, such as counting events, using time cues, and so on (see Capaldi \& Verry, 1981).

\section{GENERAL DISCUSSION}

In each of the two investigations reported here, rats were provided with a serial learning task that could be mastered by employing either single-event or multiple-event hedonic memory. The rats employed multiple-event hedonic memory despite the fact that doing so elevated responding on 0-pellet trials. Thus, the present results do not suggest that rats employ multiple-event hedonic memory only after one or more other means of anticipating reinforcement have been found to be unsatisfactory. On the contrary, the present results suggest that rats employ multiple-event hedonic memory to anticipate reinforcement despite the presence or absence of other means for doing so. This conclusion, suggested by the present data, is consistent with previous findings. First, in conventional discrimination-learning situations, in which external cues such as brightness cues are relevant and hedonic memories are irrelevant, rats nevertheless employ hedonic memories (e.g., Capaldi, Berg, \& Morris, 1975; Haggbloom, 1980; Haggbloom \& Tillman, 1980). And in such conventional discrimination-learning situations, hedonic memory can have the same effect as in the unconventional discrimination-learning situation employed here: it can greatly elevate speed of responding on $\mathrm{S}-$ trials. The evidence cited above indicates that discriminative responding will come under the control of hedonic memories even when such memories are irrelevant, with external cues such as brightness cues being relevant. The recent finding that discriminative responding comes under the control of hedonic memories when they and external cues are simultaneously relevant to discriminative responding (Haddad, Walkenbach, Preston, \& Strong, 1981) is, therefore, hardly surprising. Another instance in which multiple hedonic memory would seem to confer little or no advantage in anticipating reinforcement is in connection with various schedules of partial reinforcement, such as an irregular schedule of reinforced and nonreinforced trials. Yet multiple-event hedonic memory has been identified as the basis for the increased resistance to extinction produced by various schedules of partial reinforcement (see, e.g., Capaldi, 1966, 1967, 1979). Available evidence suggests that, at the outset of training, rats employ multiple-event hedonic memory and remember a substantial portion of the hedonic events they have received in possibly all instrumental learning situations.

As indicated in the experiments reported by Capaldi and Verry (1981), the presence or absence of reinforcement could be predicted in certain instances only by employing multiple-event hedonic memory. In those experiments, rats employed multiple-event hedonic memory both early in training and later in training, after hundreds of training trials. The early training effects are not surprising, since, as we saw above, it appears that, at the outset of any sort of instrumental training, rats employ multiple-event hedonic memory regardless of the presence or relevance of other stimuli in the learning task. But rats may continue to employ multiple-event hedonic memory later in training only when, as in the investigations of Capaldi and Verry, it is necessary to predict reinforcement and nonreinforcement. That is to say, although the available evidence strongly suggests that rats employ multiple-event hedonic memory at the outset of any sort of instrumental training, it says less about whether they continue to do so later in training when, as in most instrumental learning tasks, employing hedonic memories would not seem to be particularly useful. An exception to this may be the recently reported finding of Haddad, Walkenbach, Preston, and Strong (1981), who, through considerable training, first established discriminative responding on the basis of external cues. Subsequently, hedonic memories were made relevant along with the external cues. Even under those conditions, the hedonic memories acquired control over responding, although that control appeared to be somewhat reduced. The Haddad et al. findings suggest, then, that, at least under some conditions, hedonic memories continue to gain and exert control over responding even following considerable training.

It is possible to view the present results as follows: relatively fast running on 0 -pellet trials of three-event series represents, not poor anticipation of 0 pellets, but good anticipation of 20 pellets. That is, running may have been relatively fast on 0 -pellet trials of, say, the 20-0-20 series, because this decreased the time until Trial 3, a 20-pellet trial, occurred. This possible delay relationship may represent a mechanism through which hedonic memories affect performance. Consider Experiment 1, for example, in which each group ran faster on the 0-pellet trials of three-event than of two-event series. In Experiment 1, essentially, Group 20-0-20 discriminated between its 20-0-20 and its 2-0 series, while Group 2-0-20 discriminated between its $2-0-20$ and $20-0$ series. The ultimate basis of this discrimination could only have been the memories produced by the initial events of each series, there being no other differential cues available. The memory of the first event in each series, then, signaled either the availability of reward after a delay (three-event series) or its lack of availability (two-event series). Thus, the cues available to detect differential delays of reinforcement must have been the memories produced by the first events of 
each series. In the most general terms, this is what is being suggested by the multiple hedonic memory view, that is, that the memory of the first event of a three-event series became, on the third trial of the series, a signal for reward (together with $S^{\circ}$ ) and thus elevated responding on the second trial of the series.

\section{REFERENCES}

Capaldi, E. J. Partial reinforcement: A hypothesis of sequential effects. Psychological Review, 1966, 73, 459-477.

CAPALdi, E. J. A sequential hypothesis of instrumental learning. In K. W. Spence \& J. T. Spence (Eds.), The psychology of learning and motivation (Vol. 1). New York: Academic Press, 1967.

Capaldi, E. J. Latent discrimination learning under a regular schedule of partial reinforcement. Animal Learning \& Behavior, $1979,7,63-68$.

Capaldi, E. J., Berg, R. F., \& Morris, M. D. Stimulus control of responding in the early trials of differential conditioning. Learning and Motivation, 1975, 6, 217-229.

Capaldi, E. J., \& Molina, P. Element discriminability as a determinant of serial pattern learning. Animal Learning \& Behavior, 1979, 7, 318-322.

Capaldi, E. J., Nawrocki, T. M., \& Verky, D. R. Difficult serial anticipation pattern in rats: Rule-encoding vs. memory. Animal Learning \& Behavior, 1982, 10, 167-170.

Capaldi, E. J., \& Verry, D. R. Serial order anticipation learning in rats: Memory for multiple hedonic events and their order. Animal Learning \& Behavior, 1981, 9, 441-453.
Calpaldi, E. J., Verry, D. R., \& Davidson, T. L. Memory, serial anticipation learning, and transfer in rats. Animal Learning \& Behavior, 1980, 8, 575-585.

Crowder, R. G. Principles of learning and memory. Hillsdale, N.J: Erlbaum, 1976.

Grosslight, J. H., \& Radlow, R. Patterning effect of the nonreinforcement-reinforcement sequence in a discrimination situation. Journal of Comparative and Physiological Psychology, 1956, 49, 542-546.

Haddad, N. F., Walkenbach, J., Pregton, M., \& Strong, R. Stimulus control in a simple instrumental task: The role of internal and external stimuli. Learning and Motivation, 1981, 12, 509-520.

Haggrloom, S. J. Reward sequence and reinforcement level as determinants of S- behavior in differential conditioning. Animal Learning \& Behavior, 1980, 8, 424-428.

Hagobloom, S. J., \& Tillman, D. J. Sequential effects on discrimination reversal. Learning and Motivation, 1980, 11, 318-338.

Hulse, S. H. Cognitive structure and serial pattern learning by rats. In S. H. Hulse, H. Fowler, \& W. J. Honig (Eds.), Cognitive processes in animal behavior. Hillsdale, N.J: Erlbaum, 1978.

Seybert, J. A., Mellgren, R. L., Jobe, J. B., \& Eckert, E. Sequential effects in discrete-trials instrumental escape conditioning. Journal of Experimental Psychology, 1974, 102, 473-483.

(Manuscript received December 14, 1981; revision accepted for publication May 6, 1982.) 